\title{
Improvement of mechanical properties of long jute fiber reinforced polylactide prepared by injection molding process
}

\author{
T. Fujiura ${ }^{1}$, T. Okamoto ${ }^{2}$, T. Tanaka ${ }^{2} \&$ Y. Imaida ${ }^{2}$ \\ ${ }^{1}$ Mechanical Engineering Research Laboratory, Kobe Steel, LTD., Japan \\ ${ }^{2}$ Faculty of Science and Engineering, Department of Mechanical and \\ Systems Engineering, Doshisha University, Japan
}

\begin{abstract}
Natural plant fibers have recently been attracting attention as the reinforcements for plastics due to their high specific mechanical properties and carbon neutrality. This study investigated the preparation process for long jute fibers reinforced polylactide (LJF/PLA) pellets for injection molding, and explored improvement of mechanical properties of molded LJF/PLA composites in respect of preservation of molecular weights of PLA matrix. LJF/PLA pellets containing $50 \mathrm{mass} \%$ of jute fibers were prepared by original pultrusion process fabricated for manufacturing long fiber reinforced thermoplastic (LFT), with the excellent impregnation of resin into jute fiber bundles. Evaluation of injectionmolded specimens from LJF/PLA pellets revealed that tensile and flexural strength were dependent on molecular weights of PLA matrix, which correlatively decreased with the moisture contents of originated LJF/PLA pellets by the hydrolysis reaction. In the evaluation of chopped jute fiber reinforced PLA (Chopped-JF/PLA) prepared with ordinary extruding method and injection molding, it was revealed that severe dehydration of jute fibers prior to compounding were proven to be effective for preventing the deterioration in the molecular weight of PLA, and that better fiber dispersion in Chopped-JF/PLA than in LJF/PLA contributed to attain high mechanical properties in spite of shorter average fiber length remaining in the composites.
\end{abstract}

Keywords: long-fiber reinforced thermoplastic (LFT), polylactide (PLA), natural plant fibers, jute, moisture content, molecular weight, mechanical properties. 


\section{Introduction}

In recent years, 'Green Composites', consisting of natural-resourced polymers and biofibers, have been widely noticed as environmentally-conscious and sustainable materials. Besides gaining attention to their potential for contribution to reduction of carbon dioxide $\left(\mathrm{CO}_{2}\right)$ emission and saving of fossil resources, they have also been attracting interests in the industrial fields due to their high mechanical properties, low cost and desirable recycle features [1-4].

Among many kinds of natural-resourced polymers, polylactide (PLA) is most popular for the matrix of green composites and many researches on PLA-based composites reinforced with natural plant fibers (NF), such as jute, kenaf and hemp, have been done expecting to improve the mechanical properties of PLA [5-9]. While having excellent moldability and mechanical properties, PLA has a problem that it can easily hydrolyse at high temperature by the reaction with the moisture, resulting in drop of mechanical and thermal properties due to degradation of molecular weights. Generally, NF contains as much as $10 \mathrm{mass} \%$ of moisture in the ambient condition, which can be the cause of hydrolysis of PLA on preparing and molding the composites. Therefore, the control of moisture of the compound in the molding process would be a key issue to prevent the decomposition of PLA and to ensure the mechanical performance of the composites.

The purpose of this study is to explore the influence of hydrolysis of PLA on mechanical properties of LJF/PLA composites, and to clarify how the decomposition of PLA can be prevented in the course of compounding and molding by eliminating moistures and addition of hydrolysis retardant for improving mechanical properties and moldability of the composites.

\section{Materials and experimental procedure}

\subsection{Materials}

The matrix polymer used is polylactide TERRAMAC TE-8000 (Unitika). Bleached spun jute yarn (Tesac Corporation, yarn count:16.5) was used as the reinforcing fibers. The filament diameter of jute is about 20-100 $\mu \mathrm{m}$. As hydrolysis inhibitor of PLA, Carbodilite LA-1 (Nisshinbo) was used. In addition, PLA nonwoven mat TERRAMAC G0303WTO (Unitika) was used as the matrix together with TE-8000 for preparing chopped jute fiber reinforced PLA.

\subsection{Preparation of LJF/PLA pellets}

LJF/PLA compounds for injection molding were prepared as LFT pellets using an originally developed LFT production process. The schematic diagram of the production apparatus is shown in Figure 1. Jute yarns were induced continuously through the pre-heater for drying and then into cross head die for impregnating molten PLA resin, which was supplied from the screw extruder. The composite strand of jute/PLA was pulled out from the die, followed by cooling with water 
or air-blow and cutting into pellets in a fixed length. In addition to these general pultrusion techniques for thermoplastics, the apparatus is equipped with a novel function to twist the pultruded strand continuously at optional angles, which can contribute to reduce the pultruding force and to attain excellent resin impregnation between fiber filaments. Jute fiber content in LJF/PLA pellets was set in 50mass \% and pellets were prepared in $6 \mathrm{~mm}$ length.

Figure 2 shows the schematic image of LFT pellet derived by this original process. In the axial direction of the pellet, fiber tows are spirally incorporated in the matrix resin.

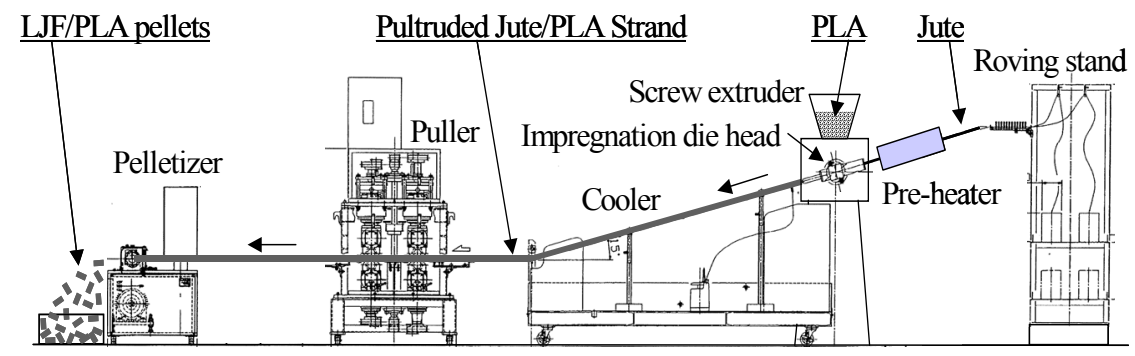

Figure 1: The schematic diagram of LFT production apparatus.

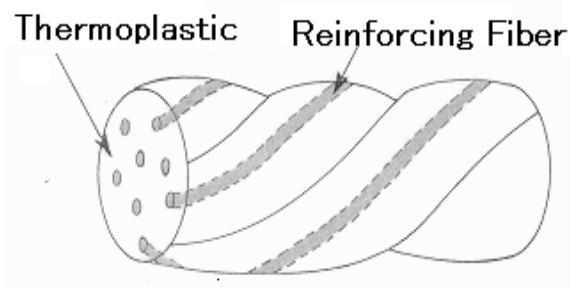

Figure 2: $\quad$ The schematic drawing of LFT pellet.

Table 1 describes the varied parameters for preparing LJF/PLA pellets. Periods of heat drying at $80^{\circ} \mathrm{C}$ prior to compounding in pultrusion were varied from 3 hours to 48 hours. Additive content of hydrolysis retardant LA-1, which was preliminarily dry-mixed with PLA resin pellets, was fixed at 1 mass $\%$ to PLA.

Table 1: $\quad$ Preparing conditions for LJF/PLA pellets.

\begin{tabular}{cccc}
\hline Sample Name & $\begin{array}{c}\text { Drying of } \\
\text { Jute Fibers }\end{array}$ & $\begin{array}{c}\text { LA-1 } \\
\text { Content } \\
{[\mathrm{mass} \%]}\end{array}$ & $\begin{array}{c}\text { Pultruding } \\
\text { Speed } \\
{[\mathrm{m} / \mathrm{min} .]}\end{array}$ \\
\hline \hline LJF/PLA $/ 0 \%$ & $80^{\circ} \mathrm{C} \times 48 \mathrm{hrs}$ & 0 & 20 \\
\hline $\mathrm{LJF} / \mathrm{PLA} / 1 \%-1$ & $80^{\circ} \mathrm{C} \times 48 \mathrm{hrs}$ & 1.0 & 20 \\
\hline $\mathrm{LJF} / \mathrm{PLA} / 1 \%-2$ & $80^{\circ} \mathrm{C} \times 6 \mathrm{hrs}$ & 1.0 & 20 \\
\hline $\mathrm{LJF} / \mathrm{PLA} / 1 \%-3$ & $80^{\circ} \mathrm{C} \times 3 \mathrm{hrs}$ & 1.0 & 20 \\
\hline
\end{tabular}




\subsection{Preparation of chopped jute fiber reinforced PLA pellets}

Chopped jute fiber reinforced PLA were prepared and evaluated to examine the effects of demoisturizing in advance of compounding on the decomposition of PLA, also aiming to compare the mechanical properties with those of LJF/PLA in terms of fiber dispersibility in the composites.

Jute spun yarn was chopped into pieces of $6 \mathrm{~mm}$ length. Those chopped fibers was mixed with TE-8000 pellets and LA-1, and mixtures were wrapped and rolled with PLA nonwoven mat TERRAMAC G0303WTO. Total content of jute was adjusted to 50 mass $\%$ in the material and LA- 1 content was set at $1.0 \%$ of total PLA weight. After the roll-shaped material was dried in the heating oven for 48 hours at $80^{\circ} \mathrm{C}$, they were put to twin screw extruder (Screw Diameter $=18 \mathrm{~mm}, \mathrm{~L} / \mathrm{d}=40)$ to be processed into composite pellets. These pellets were dried for 72 hours at $80^{\circ} \mathrm{C}$ prior to injection-molding.

\subsection{Injection molding of composites}

LJF/PLA pellets and chopped-JF/PLA pellets were injection-molded into specimens using an injection molding machine Si-100III (Toyo Kikai Kinzoku). Injection process was carried out with the cylinder temperature at $160^{\circ} \mathrm{C}$ and the mold temperature at $25^{\circ} \mathrm{C}$. As the reference sample, specimens of non-reinforced PLA were also prepared in the same manner.

\subsection{Evaluation of composite pellets and molded specimens}

Moisture contents of composite pellets were measured with infra-red moisture meter FD-720 before they were used in injection molding.

Tensile tests were performed out according to JIS K7113 using an Autograph (Shimadzu Corporation) with the crosshead speed at $1.0 \mathrm{~mm} / \mathrm{min}$. Flexural tests were done according to JIS K6911 also using an Autograph with the distance between fixed points in $150 \mathrm{~mm}$ and crosshead speed at $20 \mathrm{~mm} / \mathrm{min}$. NotchedIzod impact tests were carried out according to JIS K7062.

Furthermore, average molecular weights of PLA in the composite pellets and injection-molded samples were determined using the gel permeation chromatography (GPC) based on polystyrene standards. The analyzing system used was Waters-600 high-pressure pump equipped with Shodex GPC column LF-804 and the differential refractive index detector SE-71 (Showa Denko, Co.). GPC separation was operated using chloroform as the carrier eluent at the flow rate of $1.0 \mathrm{ml} / \mathrm{min}$, with the column temperature at $40^{\circ} \mathrm{C}$.

\section{Results and discussion}

\subsection{Characteristics of LJF/PLA pellets}

The appearance of LJF/PLA pellets is shown in Figure 3. The fact that pellets showed almost white color, which is originated from starting bleached jute and PLA matrix, suggests that discoloration or damage of jute fibers by heat rarely occurred during the pellet processing. 


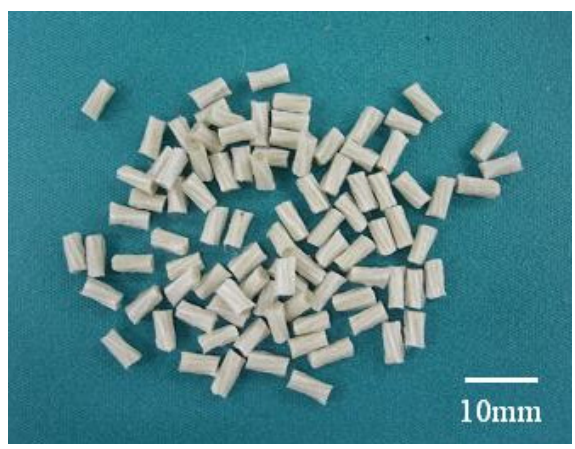

Figure 3: The appearance of LJF/PLA pellets.

\subsection{Properties of LJF/PLA composites}

Moisture contents, molecular weights of matrix PLA and mechanical properties of injection molded LJF/PLA are summarized in Table 2. Molecular weights of PLA in LJF/PLA pellets significantly diminished compared with that of raw PLA $($ TE $8000 \times 3 N)$. However, reduction in molecular weight of LJF/PLA/1\%-1 containing hydrolysis retardant was smaller compared with that of LJF/PLA/ $0 \%$ without hydrolysis retardant. LJF/PLA/1\%-1 showed little reduction in molecular weight of PLA in processing from pellets to be injection-molded. While moisture contents of pellets are different among three kinds of sample of LJF/PLA/1\%, molecular weights of PLA in injection-molded materials were almost identical. As far as this material composition is concerned, it is found that hydrolysis of PLA in injection molding can be prevented by precedingly reducing the moisture content of composite pellets below $0.8 \mathrm{wt} \%$.

Table 2: $\quad$ Properties of composite pellets and molded specimens.

\begin{tabular}{c|c|c|c|c|c|c}
\hline \multirow{2}{*}{ No. } & \multicolumn{2}{|c|}{ LFT pellets } & \multicolumn{4}{c}{ Molded specimens } \\
\cline { 2 - 7 } & $\begin{array}{c}\text { Moisture } \\
\text { Content } \\
{[\%]}\end{array}$ & $\begin{array}{c}\text { Molecular } \\
\text { weights }\end{array}$ & $\begin{array}{c}\text { Molecular } \\
\text { weights }\end{array}$ & $\begin{array}{c}\text { Tensile } \\
\text { strength } \\
{[\mathrm{MPa}]}\end{array}$ & $\begin{array}{c}\text { Flexural } \\
\text { strength } \\
{[\mathrm{MPa}]}\end{array}$ & $\begin{array}{c}\text { Izod impact } \\
\text { strength } \\
{\left[\mathrm{kJ} / \mathrm{m}^{2}\right]}\end{array}$ \\
\hline \hline LJF/PLA/0\% & 0.07 & 27,000 & 17,000 & 30.3 & 68.2 & 3.95 \\
\hline LJF/PLA/1\%-1 & 0.08 & 35,000 & 34,000 & 71.5 & 122.4 & 4.59 \\
\hline LJF/PLA/1\%-2 & 0.59 & - & 35,000 & 68.1 & 134.2 & 5.30 \\
\hline LJF/PLA/1\%-3 & 0.83 & - & 35,000 & 71.8 & 135.3 & 5.09 \\
\hline PLA(TE8000×3N) & 0.07 & 69,000 & 70,000 & 52.1 & 93.1 & 2.06 \\
\hline
\end{tabular}

Figure 3 displays the stress-strain diagram of tensile test. Due to Table 2 and Figure 3, it is obvious that LFJ/PLA/1\% materials have high tensile strength and modulus compared with non-reinforced PLA, however their strain at break were smaller than non-reinforced PLA. On the other hand, both strength and strain of 


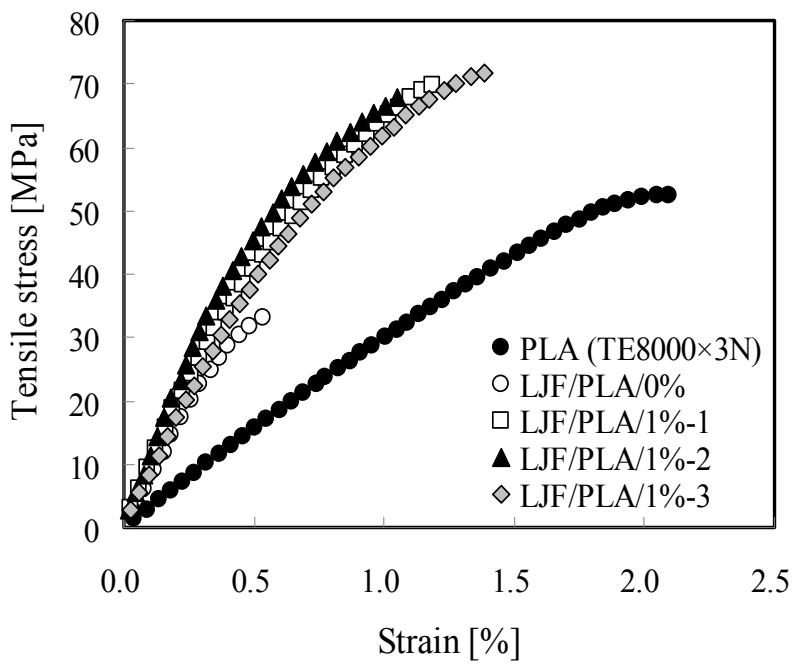

Figure 4: Tensile stress-strain curves of LJF/PLA and Non-reinforced PLA specimens.

LJF/PLA/0\% material were drastically turned down. These results can conclude that molecular weights of PLA in composite have a large impact on their mechanical properties.

\subsection{Effect of fiber drying and dispersibility on mechanical properties of composites}

Fabrication process of compounds with LFT manufacturing equipment has advantages that composite pellets containing over $50 \mathrm{wt} \%$ of jute can be easily prepared and that fibers are hardly damaged by heat because of the very short period of resin impregnation in processing. However, there is a problem that online drying of jute tends to be insufficient at high pultruding speed, which causes incomplete removal of moisture. In addition, fiber dispersibility of such LFTs in injection molding is often poor. Therefore, in this study, composite pellets were prepared using well-dried chopped jute fiber with twin screw extruder and

Table 3: $\quad$ Properties of chopped-JF/PLA pellets and molded specimens.

\begin{tabular}{c|c|c|c|c|c|c}
\hline Sample Name & \multicolumn{2}{|c|}{ Extruded Pellets } & \multicolumn{3}{|c}{ Injection-molded Specimens } \\
\cline { 2 - 7 } & $\begin{array}{c}\text { Mo isture } \\
\text { contents }\end{array}$ & $\begin{array}{c}\text { Molecular } \\
\text { weights of } \\
\text { PLA } \\
{[-]}\end{array}$ & $\begin{array}{c}\text { Molecular } \\
\text { weights of } \\
\text { PLA } \\
{[-]}\end{array}$ & $\begin{array}{c}\text { Tensile } \\
\text { strength } \\
{[\mathrm{MPa}]}\end{array}$ & $\begin{array}{c}\text { Flexural } \\
\text { strength } \\
{[\mathrm{MPa}]}\end{array}$ & $\begin{array}{c}\text { Izod impact } \\
\text { strength } \\
{\left[\mathrm{kJ} / \mathrm{m}^{2}\right]}\end{array}$ \\
\hline \hline Chopped-JF/PLA & 1.43 & 57,000 & 56,000 & 79.2 & 143.1 & 3.76 \\
\hline PLA & 0.06 & 62,000 & 61,000 & 63.7 & 105.6 & 2.37 \\
\hline
\end{tabular}


properties of injection molded chopped-JF/PLA were evaluated to clarify the effect of fiber drying and dispersibility in comparison with those of LJF/PLA. Table 3 shows the results of evaluation on chopped-JF/PLA and Figure 5 displays the molecular weights of both of JLF/PLA and chopped-JF/PLA composites.

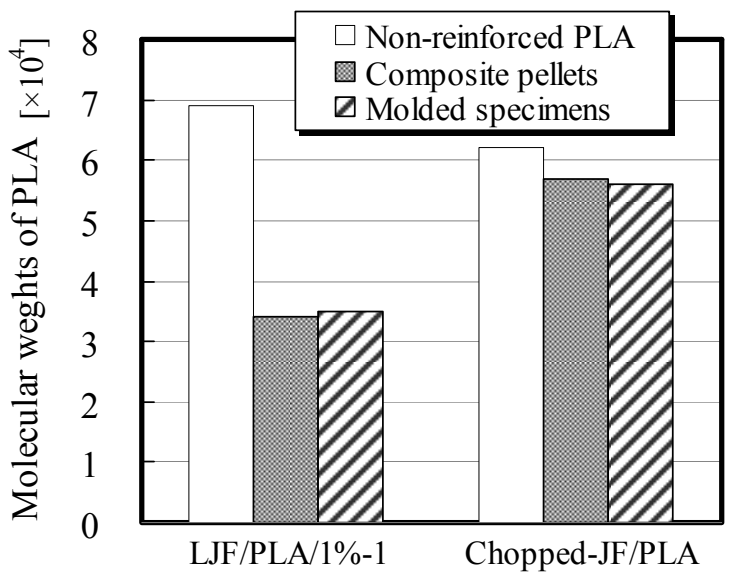

Figure 5: Comparison of molecular weight of matrix PLA of LJF/PLA and chopped-JF/PLA composites.

Molecular weight of PLA in chopped-JF/PLA did not show much decrease from that of raw PLA. This result indicates that severe drying of jute and addition of hydrolysis retardant is effective for preventing the deterioration of PLA. Mechanical properties of injection-molded material were almost same as those of LJF/PLA/1\% shown in Table 2, which has much lower molecular weight of PLA matrix. By visual observation, jute fibers were excellently dispersed in choppedJF/PLA specimens, however, residual fiber length in them seemed much shorter than that in LJF/PLA composites. In such preparing method of LJF/PLA composites as shown in this study, improvements of mechanical properties of molded parts can be expected if severe removal of moisture in LFT compounding process for avoiding decomposition of PLA and better fiber dispersion with remaining long fiber length are attained.

\section{Summary}

(1) LJF/PLA composites showed higher mechanical properties compared with non-reinforced PLA. In spite of preceding heat-drying of jute yarns, molecular weights of PLA matrix considerably dropped from that of starting PLA. However, addition of hydrolysis retardant was found to be effective for preventing the further reduction of molecular weight of PLA in injection molding. 
(2) In the evaluation of chopped-JF/PLA, it is revealed that sufficient drying of jute can avoid the deterioration of PLA and that better fiber dispersion is expected to be effective for improvements of mechanical properties of composites.

\section{References}

[1] Nabi Saheb, D. \& Jog, J. P., Natural fiber polymer composites: A review. Advances in Polymer Technology, 18(4), pp. 351-363, 1999.

[2] Arzondo, L. M., Perez, C. J. \& Carella, J. M., Injection molding of long sisal fiber-reinforced polypropylene: Effects of compatibilizer concentration and viscosity on fiber adhesion and thermal degradation. Polymer Engineering and Science, 45, pp. 613-621, 2005.

[3] Shito, T., Okubo, K., \& Fujii, T., Development of eco-composites using natural bamboo fibers and their mechanical properties. High Performance Structures and Composites (HPSC2002), WIT press, pp. 175-182, 2002.

[4] Aichholzer, W., Natural fibre applications in automotive manufacturing. Proc. of $6^{\text {th }}$ Global Wood and Natural Fibre Composites Symposium, org. Institute fuer Werkstofftechnik Kunststoff- und Rycyclingtechnik, University of Kassel, pp. A11-1 - A11-9, 2006.

[5] Takagi, H., Latest fiber reinforced plastics: Advanced application examples and future technologies. Environment-friendly FRP made from natural fiber reinforced materials. Engineering Materials, 54(4), pp. 51-54, 2006.

[6] Bogren, K. M, Gamstedt, E. K., Neagu, R. C., Aåkerholm, M. \& LindstroÖm, M., Dynamic-mechanical properties of wood-fiber reinforced polylactide: Experimental characterization and micromechanical modelling. Journal of Thermoplastic Composite Materials, (19)6, pp. 613-637, 2006.

[7] Ben, G., Kihara, Y. \& Aoki, Y., Optimum molding conditions for fabricating green composites composed of kenaf fibers and PLA resin. Proc. of the $4^{\text {th }}$ Int. Workshop on Green Composites, org. The Committee on Composite Materials, The Society of Materials Science, Japan, pp. 106-111, 2006.

[8] Fujiura, T., Tanaka, T. and Imaida, Y., A study on mechanical performance of composites injection-molded from jute fiber reinforced polylactic acid. Kyoka Plastics, 53(10), pp. 430-436, 2007.

[9] Fujiura, T., Sakamoto, K., Tanaka, T. and Imaida, Y., A study on preparation and mechanical properties of long jute fiber reinforced polylactic acid by the injection molding process. $4^{\text {th }}$ International Conference on High Performance Structures and Materials (HPSM 2008), pp. 231-240, 2008. 